\section{The Role of GM-CSF in Multiple Sclerosis}

\section{A. Schottelius ${ }^{1}$ \\ ${ }^{1}$ Chief Development Officer, MorphoSys AG, Martinsried}

Multiple sclerosis (MS) is an idiopathic inflammatory disease of the central nervous system, which is characterized pathologically by demyelination and subsequent axonal degeneration. Infiltrating macrophages have been identified to contribute significantly to demyelination in both clinical MS and animal models of MS. GM-CSF stimulates proliferation and activation of macrophages, monocytes, neutrophils, eosinophils, dendritic cells and microglia with subsequent induction of pro-inflammatory biomolecules. GM-CSF might therefore be involved in the inflammatory processes related to MS. Elevated concentrations of GM-CSF have been shown in the cerebrospinal fluid but not in the serum of patients suffering from relapsing-remitting or secondary progressive MS $[1,2]$. Similarly, GM-CSF levels were reported to be higher in the cerebrospinal fluid, but not in the serum of patients with active phase of relapsing-remitting MS and in patients with remission in comparison to control patients suffering from other non-inflammatory neurological diseases [3].

Additional preclinical findings support a role of anti-GM-CSF therapy for MS. GM-CSF -/- mice are resistant to EAE and administration of an anti-GM-CSF antibody prevented the onset of clinical disease. In contrast, the administration of recombinant GM-CSF worsened the disease in the EAE mouse model [4]. Moreover it was observed that autoreactive T cells are the source of GM-CSF responsible for EAE and that GM-CSF serves a non-redundant function in the initiation of this autoimmune inflammation [5-7]. In addition it has been shown that GM-CSF is required for recruitment of peripheral myeloid cells into the CNS and the ability of systemic myeloid cells to respond to GM-CSF was found to be critical for the development of EAE [6,8].
Blockade of GM-CSF activity might thus be a therapeutic approach in the treatment of inflammatory diseases such as MS. MOR103 is a fully human monoclonal antibody (mAb) directed towards human GM-CSF. Preclinical studies have shown that MOR103 neutralizes the biological function of human GM-CSF and significantly reduces inflammation by blocking its interaction with cell surface receptors of inflammatory cells, thus inhibiting their activation. These studies suggest that GM-CSF is involved in the pathogenesis of autoimmune diseases such as rheumatoid arthritis and multiple sclerosis.

In September 2012, MorphoSys announced results from the phase 1b/2a clinical trial evaluating MOR103 in rheumatoid arthritis (RA) patients. The positive data make MOR103 the first anti-GM-CSF antibody to demonstrate clinical efficacy in RA and underline the compound's potential to become an important new drug in an area of unmet medical need. The safety of MOR103 in patients with MS is currently being investigated in a phase Ib trial in Europe. MOR103 has recently been licensed to GlaxoSmithKline.

Conflict of Interest: Arndt Schottelius is employed by MorphoSys AG.

\section{References \\ 1 Perella et al. Eur Neurol 1993; 33: 152-155 \\ 2 Mellegård et al. Mult Scler 2010; 16: 208-217 \\ 3 Carrieri et al. Immunopharmacol Immunotoxicol 1998; 20: 373-382 \\ 4 McQualter et al. J Exp Med 2001; 194: 873-881 \\ 5 Ponomarev et al. J Immunol 2007; 178: 39-48 \\ 6 Codarri et al. Nature Immunol 2011; advance online publication \\ 7 El-Behi et al. Nature Immunol 2011; advance online publication \\ 8 King et al. Blood 2009; 113: 3190-3197}

\section{Bibliography}

DOI http://dx.doi.org/10.1055/s-0033-1346708

Drug Res 2013; 63, Suppl. 1: S8-S8

(c) Georg Thieme Verlag KG Stuttgart · New York .

ISSN 2194-9379

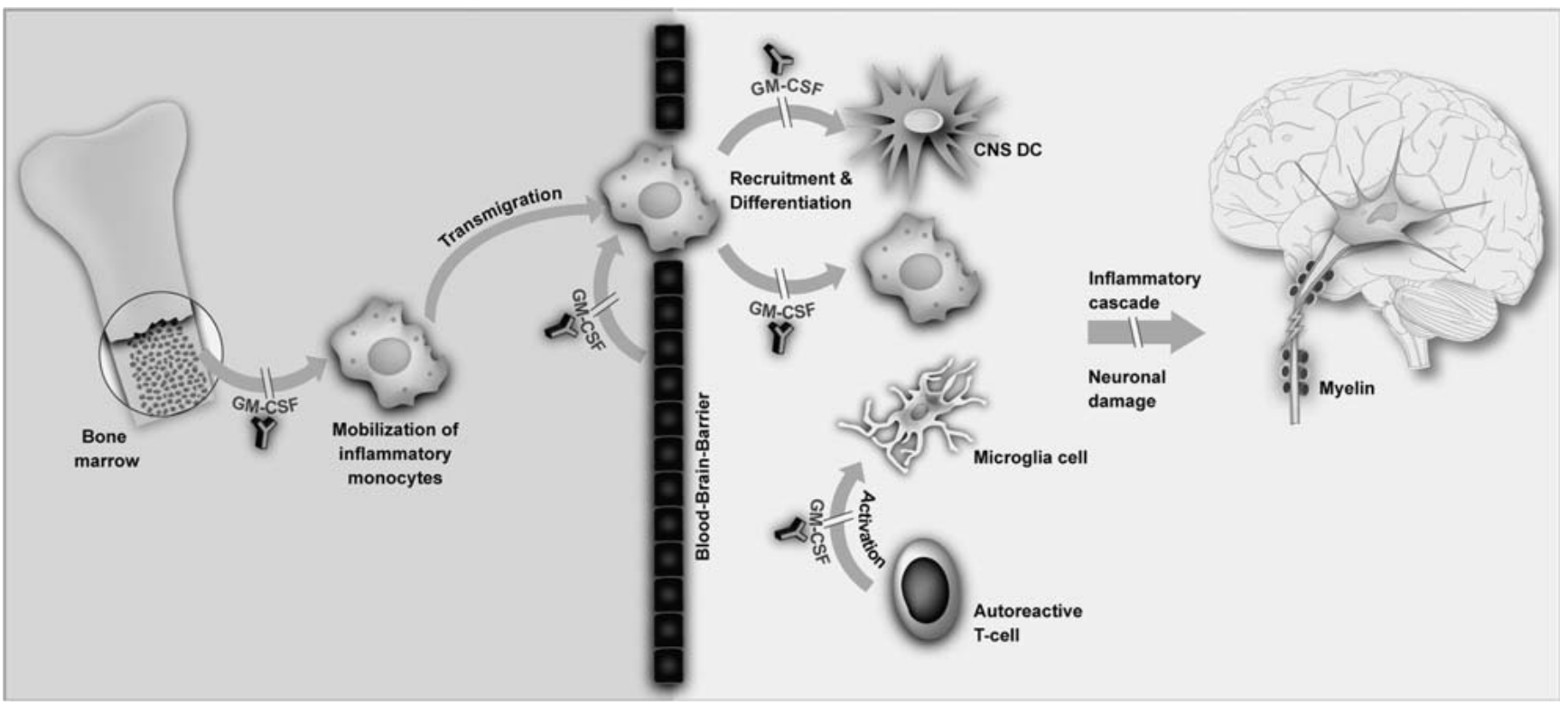

